IMEJ: Islamic Management and Empowerment Journal

Volume 1, Number 2, Desember 2019. p. 205 - 216

P-ISSN:2685-953X; e-ISSN:2686-0317

DOI: 10.18326/imej.v1i2.205-216

website: http://e-journal.iainsalatiga.ac.id/index.php/imej

\title{
Pengembangan Pariwisata Berbasis Masyarakat di Blue Lagon, Sleman Yogyakarta
}

\author{
Hafni Khairunnisa ${ }^{1}$ \\ IAIN Syekh Nurjati Cirebon, Indonesia \\ 1hafni.k@gmail.com
}

\begin{abstract}
This study aims to find out how tourism development strategies are carried out by the Blue Lagoon community. The research method used is a descriptive qualitative research method. Sources of data in this study were obtained from interviews with sources as well as observations and archives or documents, literature studies. The sampling technique uses purposive sampling. Data analysis in this study uses an interactive analysis model. Based on the results of the study it can be seen that the strategy of developing a tourism village carried out by the community is by forming a tourism village management committee, making tour packages, building supporting facilities, promotion programs and cooperation with various interested parties. Through the tourism development strategy, it is seen how tourism empowerment has fostered community participation, established cooperative relationships and improved the economy of the community around the tourism area.
\end{abstract}

Keywords: Development Strategy, Tourism Village

\begin{abstract}
Abstrak
Penelitian ini bertujuan untuk mengetahui bagaimana strategi pengembangan pariwisata yang dilakukan oleh masyarakat Blue Lagoon. Metode penelitian yang dilakukan adalah metode penelitian deskriptif kualitatif. Sumber data dalam penelitian ini diperoleh dari Wawancara dengan narasumber serta observasi dan arsip atau dokumen, studi literature. Teknik penarikan sampel menggunakan purposive sampling. Analisis data pada penelitian ini menggunakan model analisis interaktif. Berdasarkan hasil penelitian dapat diketahui bahwa strategi pengembangan desa wisata yang dilakukan oleh masyarakat adalah dengan membentuk panitia pengelola desa wisata, membuat paket wisata, pembangunan sarana pendukung, program promosi dan kerja sama dengan berbagai pihak yang berkepentingan. Melalui strategi pengembangan wisata tersebut terlihatlah bagaimana pemberdayaan wisata telah menumbuhkan partisipasi masyarakat, terjalinnya hubungan kerja sama dan peningkatan perekonomian masyarakat di sekitar wilayah pariwisata.
\end{abstract}

Kata Kunci: Pengembangan, Desa wisata 


\section{Pendahuluan}

Amanat GBHN salah satunya adalah peningkatan ekonomi masyarakat yang menjadi salah satu sektor andalan bagi Indonesia untuk meningkatkan perekonomian dengan cara mengembangkan industri pariwisata. Pariwisata sebagai sebuah industri dipandang fleksibel karena mampu memanfaatkan sumber daya yang tersedia di sekitarnya. Indonesia merupakan negara yang memiliki keanekaragaman sumber daya yang dapat dimanfaatkan untuk kegiatan pariwisata.

Kota Yogyakarta memiliki kekayaan sumber daya yang sangat beragam seperti pantai, gunung, budaya, heritage, buatan dan lain sebagainya. Hal tersebut menjadikan Yogyakarta sebagai salah satu daerah yang memiliki banyak potensi wisata yang jika dikembangkan akan menambah ragam destinasi wisata di Yogyakarta dan akan memberikan dampak ekonomi yang positif bagi daerah ini. Provinsi Daerah Istimewa Yogyakarta secara administratif terbagi menjadi 3 Kabupaten dan 1 kota. Kabupaten Sleman sebagai salah satu kabupaten di DIY memiliki berbagai potensi wisata yang dapat dikembangkan. Sejak tahun 2003 pengembangan pariwisata berbasis masyarakat mulai digencarkan (Dinas Pariwisata Sleman, 2016). Hal ini selain mendapatkan keuntungan berupa ekonomi tetapi juga akan menguntungkan dari sisi keberlanjutan pariwisata.

Salah satu bentuk konkret implementasi pariwisata berbasis komunitas adalah desa wisata. Desa wisata merupakan bentuk pengembangan dari wisata pedesaan. Pariwisata pedesaan adalah pengembangan daerah pedesaan menjadi daerah tujuan wisata dengan menonjolkan berbagai keunikan yang ada, seperti lingkungan alam, flora dan fauna yang beraneka ragam, dan kehidupan sosial masyarakat pedesaan (Suhardjo, 2008).

Indikator desa wisata yang paling utama adalah dari sisi keterlibatan masyarakat desa baik dalam manajerial dan partisipasi masyarakat. Konsep pengembangan pariwisata berbasis masyarakat menekankan pada pembangunan pariwisata dari masyarakat, oleh masyarakat dan untuk masyarakat. Hal ini selaras dengan program pemberdayaan masyarakat yang menghendaki masyarakat lebih berdaya dan memberikan manfaat. Masyarakat dalam hal ini diwajibkan berperan aktif maupun komprehensif di setiap tahapan pengembangan pariwisata, mulai tahap perencanaan, pembangunan, pengelolaan, pengembangan, hingga 
tahap monitoring dan evaluasi (Hadiwijoyo, 2012; Demartoto, 2009; Brohman, 1996; Suansri 2003; Bank Dunia dalam Nugroho, 2011; Nuryanti, 2015). Pariwisata berbasis masyarakat juga bertujuan menciptakan keseimbangan dan keselarasan masing-masing kepentingan stakeholders dalam pengembangan pariwisata, seperti pemerintah, swasta dan masyarakat (Demartoto dkk, 2009).

Rogi (2015) menyatakan bahwa pengembangan pariwisata berbasis masyarakat diimplementasikan sebagai desa wisata yang merupakan pengembangan dari wisata pedesaan (village tourism). Desa wisata dapat menjadi solusi alternatif strategis dalam pengembangan kegiatan pariwisata. Bukan hanya menambah kuantitas dan kualitas destinasi tetapi juga mampu meningkatkan ekonomi masyarakat lokal serta menjadi lahan aktualisasi bagi masyarakat untuk menyalurkan bakat dan kreativitasnya. Pengembangan desa wisata juga dianggap mampu meminimalkan potensi urbanisasi masyarakat dari perdesaan ke perkotaan. Selain itu, juga mampu membuka lapangan kerja baru, sehingga membuka peluang usaha untuk mengurangi jumlah pengangguran yang ada di masyarakat setempat.

Penelitian tentang pengembangan pariwisata berbasis masyarakat menjadi topik yang banyak dikaji oleh peneliti di Indonesia. Hal ini dilandasi dengan naiknya trend pengembangan pariwisata berbasis masyarakat, di mana konsep pariwisata ini memiliki tujuan untuk memberdayakan masyarakat. Beberapa penelitian yang telah dilakukan adalah Assyifa (2014), Febriyani (2016). Komponen yang diperhatikan dalam pengembangan pariwisata berbasis masyarakat, mengacu pada atraksi, promosi, fasilitas dan infrastruktur, kelembagaan.

Secara geografis Kabupaten Sleman sebagian besar merupakan daerah pedesaan sehingga hal ini merupakan peluang untuk menciptakan pemerataan peningkatan kesejahteraan, peningkatan ekonomi dan sosial masyarakat. Dari data dinas pariwisata Kabupaten Sleman pada tahun 2017 terdapat 39 desa wisata di Kabupaten Sleman. Perkembangan desa wisata sendiri mengalami pasang dan surut. Beberapa desa wisata mengalami pergeseran status tetapi banyak juga desa wisata yang baru berdiri. Desa wisata Blue Lagoon termasuk salah satu pendatang baru desa wisata yang diresmikan menjadi desa wisata sejak tahun 2015. Penelitian ini bertujuan untuk mengetahui bagaimana pengembangan pariwisata berbasis masyarakat di Desa Wisata Blue Lagoon yang telah dilaksanakan oleh masyarakat. 


\section{Metode Penelitian}

Lokasi penelitan dilaksanakan di Blue Lagoon Desa Widodomartani, Sleman Yogyakarta. Adapun sumber informasi diperoleh dari data primer dan data sekunder. Jenis penelitian yang digunakan adalah penelitian deskriptif kualitatif. Hasil penelitian ini ditekankan pada pemberian gambaran secara obyektif tentang keadaan yang sebenarnya dari obyek yang diteliti. Data primer diperoleh langsung di lapangan dengan teknik pengumpulan data purposive sampling yaitu Wawancara kepada pengurus desa wisata Blue Lagoon, Aparat dusun Blue Lagoon dan pihak berkepentingan lainnya. Wawancara dilakukan dengan memberikan sejumlah daftar pertanyaan terbuka dan tertutup. Data yang dikumpulkan dengan menggunakan kuesioner, yaitu kapasitas manajerial dan pengelola, peran serta masyarakat, atraksi dan daya tarik wisata, amenitas, aksesibilitas, kepemilikan asset, tingkat kunjungan wisatawan, dan pemasaran.

Data sekunder diperoleh dengan melakukan survey lapangan, disertai studi literature yang menunjang dan relevan dengan penelitian (baik berupa laporan-laporan dari instansi terkait, hasil penelitian terdahulu, dan sebagainya). Teknik analisis data yang digunakan menggunakan analisis interaktif yaitu reduksi data, sajian data serta penarikan kesimpulan (Sutopo, 2002). Data-data yang telah terkumpul kemudian dilakukan pemilahan data yang dapat digunakan dalam penelitian ini. Data kemudian disajikan dalam kalimat-kalimat dan proses akhirnya adalah penarikan kesimpulan.

\section{Hasil dan Pembahasan}

\section{Kajian Pengembangan Wisata Berbasis Masyarakat}

Menurut UU No. 6 Tahun 2014 Pasal 18 dijelaskan bahwa desa memiliki kewenangan di bidang penyelenggaraan pemerintahan, pembangunan desa, pembinaan kemasyarakatan, dan pemberdayaan masyarakat desa (Trisnawati dkk, 2018: 30). Hal ini menunjukkan bahwa pemerintah desa dan masyarakatnya diposisikan sebagai subyek pembangunan yang aktif dalam mengelola program pembangunan mulai dari perencanaan, pelaksanaan dan evaluasi. Desa yang memiliki potensi wisata diberikan kesempatan dan kewenanganan dalam mengelola wisata untuk kesejahteraan masyarakat. 
Pentingnya peran pariwisata dalam pembangunan masyarakat telah diatur dalam Undang-Undang Nomor 9 Tahun 1990 tentang Kepariwisataan. Pasal 3 Undang-Undang tersebut menyebutkan bahwa tujuan penyelenggaraan wisata adalah memperkenalkan, mendayagunakan, melestarikan dan meningkatkan mutu objek dan daya tarik wisata; memupuk rasa cinta tanah air dan meningkatkan persahabatan antar bangsa; memperluas dan meratakan kesempatan berusaha dan lapangan kerja, meningkatkan pendapatan nasional dalam rangka meningkatkan kesejahteraan dan kemakmuran rakyat; serta mendorong pendayagunaan produksi nasional (Wahyun, 2018: 84).

Pengembangan pariwisata berbasis komunitas pada hakekatnya harus memperhatikan beberapa poin penting, yaitu 1) Ekonomi ketersediaan dana, terciptanya lapangan kerja, adanya pendapatan; 2) Sosial peningkatan kualitas hidup, kebanggaan komunitas, pembagian peran yang adil antara laki-laki dan perempuan, generasi muda dan tua, serta semakin kuatnya organisasi komunitas; 3) Budaya pemahaman mengenai carrying capacity area, pengelolaan sampah, dan kesadaran akan perlunya konservasi; 4) Lingkungan pemahaman akan carrying capacity area, pengelolaan sampah, dan kesadaran akan perlunya konservasi; 5) Politik partisipasi masyarakat lokal, peningkatan kekuasaan komunitas yang lebih luas, dan adanya jaminan hak-hak dalam pengelolaan SDA (Suhardjo : 2008).

Desa wisata merupakan salah satu program desa yang dimaksudkan untuk menarik wisatawan dating dan mengunjungi desa tersebut. Kedatangan wisatawan diharapkan akan menambah pendapatan desa dan meningkatkan kwalitas hidup masyarakat di desa wisata tersebut (Ahda, 2017 90). Desa wisata adalah pengembangan daerah pedesaan menjadi daerah tujuan wisata dengan menonjolkan berbagai keunikan yang ada, seperti lingkungan alam, flora dan fauna yang beraneka ragam, dan kehidupan sosial masyarakat pedesaan Selain daya tarik unik, pengembangan desa wisata juga harus didukung ketersediaan sarana pendukung berupa: (a) akomodasi bersih dan nyaman (hotel dan fasilitas akomodasi untuk meningkatkan pelayanan selama dalam perjalanan); (b) fasilitas dan pelayanan pendukung untuk menambah kepuasan wisatawan (agen perjalanan, biro perjalanan, restoran dan tempat pelayanan makanan lain, toko cinderamata, bank, pusat informasi, salon, fasilitas kesehatan, keamanan, polisi, dan pemadam kebakaran); (c) aksesibilitas (kenyamanan transport, kualitas jalan menuju ODTW baik dengan jarak 
tempuh terjangkau); (d) infrastruktur (ketersediaan sumber pemasok air bersih, listrik, tempat pembuangan limbah, kemudahan sarana komunikasi); dan (e) kelembagaan (guna menjalankan aktifitas pariwisata, pengembangan, pengelolaan, pemasaran, promosi, pembuatan struktur organisasi, system control dan kebijakan investasi) (Putra, 2006; Inskeep, 1991; Hernowo, 2000).

Pengembangan desa wisata juga harus memperhatikan prinsip, (a) tidak bertentangan dengan adat istiadat atau budaya masyarakat desa setempat; (b) pembangunan fisik ditujukan untuk meningkatkan kualitas lingkungan desa; (c) memperhatikan unsur kelokalan dan keaslian; d) memberdayakan masyarakat desa wisata e) memperhatikan daya dukung, daya tampung , serta berwawasan lingkungan (Laporan Akhir DIY 2014 dalam Asyifa 2015).

Pernyataan tersebut di atas, diperkuat dengan pernyataan Inskeep (1991) yang mengatakan bahwa pengembangan pariwisata pedesaan harus memperhatikan beberapa kriteria, seperti (a) kepentingan selaras dengan upaya pelestarian warisan budaya dan warisan lokal/keaslian lingkungan alam sekitar; (b) kepentingan bermanfaat bagi penduduk/masyarakat pedesaan; (c) kepentingan bermanfaat bagi pengunjung baik dari aspek pendidikan, pengalaman dan rekreasi; (d) kepentingan berupaya meningkatkan kepuasan pengunjung; E) pengembangan dan pemanfaatan desa sebagai produk wisata (Inskeep, 1991).

Lokasi desa wisata blue lagoon berada pada 74005 LS - 7 45’ 24 LS dan 110 24' 30 BT - 110 29' 03 BT. Sedangkan secara administratf, Desa Blue Lagoon Dusun Dalem berada di wilayah Desa Widodomartani, Kecamatan Ngemplak, Kabupaten Sleman, Provinsi DIY. Dusun Dalem berada di kawasan Desa Wisata Blue Lagoon ini berada lebih kurang 17 km dari Kota Yogyakarta dengan batas wilayah sebagai berikut (a) Sebelah Utara berbatasan dengan Dusun Jangkang, Desa Widodomartani, Kecamatan Ngemplak, (b) Sebelah Selatan berbatasan dengan Dusun Kemasan, Desa Widodomartani, Kecamatan Ngemplak, (c) Sebelah Barat berbatasan dengan Dusun Jetis, Desa Widodomartani, kecamatan ngemplak, (d) Sebelah timur berbatasan dengan Dusun Pucangan, Desa Widodomartani, Kecamatan Ngemplak. Luas wilayah Kecamatan Ngemplak, Sleman seluas 35,71 km atau sekitar 6,21\% dari luas seluruh wilayah Kabupaten Sleman. Desa Widodomartani memiliki luas wilayah $6,15 \mathrm{~km}$. 


\section{Strategi Pengembangan Desa Wisata Blue Lagon oleh Masyarakat}

Pengembangan Desa Wisata Blue Lagoon dilakukan sepenuhnya oleh masyarakat. Hal ini merupakan strategi yang dilakukan oleh mayarakat lokal dalam pengembangan Desa Wisata Blue Lagoon. Desa wisata Blue Lagoon memiliki banyak menyimpan beraneka ragam potensi seperti potensi alam, budaya, buatan, religi, mata air.

Mata air yang telah dikembangkan dan menjadi tujuan utama para wisatawan adalah Sendang Pulungan atau yang lebih dikenal dengan Blue Lagoon Tirta Budi. Sendang lainnya yang juga terdapat di Desa Blue Lagoon tetapi belum dikembangkan adalah Sendang Lanang dan Sendang Wadon. Pemetaan potensi di Desa Wisata Blue Lagoon terdiri dari potensi alam, budaya, religi, kuliner, kerajinan, dan potensi buatan lainnya.

Potensi alam selain Sendang Pulungan, Sendang Lanang dan Sendang Wadon, di Desa Wisata Blue Lagoon juga terdapat aliran sungai yang dapat digunakan untuk kegiatan susur sungai. Sungai ini memiliki mata air yang bersumber dari Kaliurang, Pancuran dan Padas Gempal. Potensi Pertanian yaitu wisata sawah. Potensi Budaya yang dimiliki antara lain yaitu Upacara Merti Sumber yang diadakan setiap tahunnya, Karawitan, Saparan Ki Ageng Wonolelo yang dilaksanakan setiap bulan Sapar, Kethoprak, Kesenian Bergudo (prajurit), tari-tarian untuk perempuan Tari Jawa dan untuk lelaki kesenian Jathilan . Di Desa Blue Lagoon juga terdapat Candi Sambisari dan Museum Perjuangan Plataran yang sayangnya belum dioptimalkan dengan baik. Potensi Wisata Religi terdapat Ziarah Makam Kyai Pulungan dan Ziarah Makam Ki Ageng Wonolelo.

Potensi Kuliner merupakan hasil kreasi masyarakat Desa Blue Lagoon dalam hal pengolahan kuliner. Produk kuliner yang dihasilkan meliputi jajanan tradisional, nasi liwet, wedang jahe serai, es crea, bakso turi, tempe, dan sebagainya. Terdapat rencana untuk membangun kampung kuliner dan sudah diisi beberapa stand makanan, tetapi warung yang mengisi masih menjual makanan instan seperti pop mie bukan kuliner lokal khas Blue Lagoon. Mayoritas masyarakat di Desa Wisata Blue Lagoon merupakan tukang bamboo, tukang kayu ataupun tukang batik. Potensi kerajinan di Desa Blue Lagoon cukup besar karena SDM yang dimilikinya mampu menghasilkan kesenian seperti ukiran, anyaman, bambu, gerabah atau betik. Kendala terbesar yang dimiliki adalah kurangnya SDM dalam hal pemasaran dan desain, karena desain yang 
dihasilkan oleh pengrajin masih standar.

Desa Wisata Blue Lagoon juga mengembangkan potensi wisata buatan untuk menambah variasi potensi wisatanya. Potensi wisata buatan yang dikembangkan adalah Kolam Pancing (wisatawan dapat memancing ikan yang disediakan pengelola di tempat khusus), outbond, belajar batik, belajar anyam bambu, terapi batu kerikil, permainan ketangkasan, paguyuban gerobak sapi dan belajar perikanan. Atraksi lainnya adalah foto pada saat malam hari. Pada malam hari, terdapat angle yang sangat bagus dan dapat mengeluarkan spectrum cahaya sehingga bagi fotografer malam hari adalah saat yang tepat untuk berkunjung ke blue lagoon.

\section{Pembentukan Manajemen Desa Wisata}

Salah satu syarat yang harus terdapat dalam desa wisata adalah keberadaan manajemen pengelola desa wisata dan keterlibatan masyarakat desa dalam kegiatan desa wisata. Desa Wisata Blue Lagoon termasuk baru dalam kancah desa wisata di Kabupaten Sleman, DIY. Resmi dibuka pada tahun 2014 dengan nama Pemandian Tirtha Budhi Blue Lagoon. Desa Wisata Blue Lagoon diresmikan oleh Bupati Sleman Sri Purnomo pada 15 Maret 2015 yang kala itu bertepatan dengan hari air sedunia.

Desa Wisata Blue Lagoon terus berusaha untuk melakukan pengembangan desa wisata. Sebelum ditetapkan sebagai desa wisata pada September, 2014 dibentuklah terlebih dahulu panita pra desa wisata. Berdasarkan pembentukan panitia pra-desa wisata maka kemudian terbentuklah panitia pengelola desa wisata yang kemudian bertugas menangani kegiatan wisata di Desa Wisata Blue Lagoon. Pelindung dari organisasi ini ialah Bapak Suhadi. Pada saat terbentuknya, fokus kerja dari panitia pengelola desa wisata masih terpusat pada pengelolaan Sendang Pulungan (Blue Lagoon Tirta Budhi), namun dengan seiring berjalannya waktu fokus kerja dari pengelola desa wisata mulai berinovasi untuk mengembangkan potensi lainnya. Susunan organisasi terdapat pelindung, penasehat, ketua umum, wakil ketua, sekretaris, bendahara dan seksiseksi seperti keamanan, kebersihan, parkir, pembangunan dan dokumentasi. Organisasi ada pengelola dan kelompok sadar wisata.

Pelibatan masyarakat dalam kegiatan desa wisata dengan melibatkan masyarakat sebagai pendukung kegiatan wisata. Kendala yang dihadapi Blue Lagoon, bahwa sejauh ini tujuan wisatawan baru sebatas 
berkunjung ke Sendang Pulungan (Blue Lagoon Tirta Budhi). Sudah terdapat beberapa rumah yang menyediakan homestay jika ada wisatawan yang akan mengambil paket wisata live in, tetapi hasilnya belum sesuai harapan. Pengelolaan di Sendang Pulungan juga sepenuhnya dilakukan oleh masyarakat, hal ini juga mampu menekan angka pengangguran.

\section{Pembuatan Paket Wisata dan Pembangunan Sarana Pendukung}

Paket wisata ditawarkan wisatawan yang akan atau hendak berkunjung ke desa wisata Blue Lagoon. Dengan adanya paket wisata, dapat memberikan keleluasaan kepada wisatawan untuk memilih paket wisata yang dikehendakinya. Pembuatan paket wisata sendiri bertujuan untuk memeratakan kunjungan wisatawan bukan hanya ke atraksi utama (Sendang Pulungan) tapi juga semua potensi yang dimiliki desa wisata dapat dikelola dengan baik. Paket wisata yang telah tersedia di Desa Wisata Blue Lagoon adalah (a) Paket Outbond, (b) Paket Susur Sungai, (c) Paket Wisata Pertanian, (d) Paket Belajar Batik, (e) Paket Belajar Anyam Bambu, (f) Paket Wisata Kuliner, (g) Paket Live in.

Sarana pendukung yang saat ini masih diusahakan oleh pengelola desa wisata berupa sarana permainan untuk permainan air, kapalkapalan, dan sebagainya. Pada tahun 2016 ini, pengelola Desa Wisata Blue Lagoon telah mengembangkan satu inovasi baru yaitu kampung kuliner. Kampung kuliner ini memiliki lokasi yang berdekatan dengan Sendang Pulungan (Blue Lagoon Tirta Budhi). Kampung kuliner bertujuan untuk lebih mempopulerkan potensi kuliner lokal di desa wisata Blue Lagoon. Beberapa warung telah terlihat mengisi spot di kampung kuliner, akan tetapi dari beberapa warung belum ada yang benar-benar menjual makanan lokal. Hampir semua warung menjajakan makanan instant. Melihat situasi seperti itu, pengelola tidak hanya tinggal diam tetapi akan merubah sistem sehingga nantinya makanan yang dijajakan adalah makanan lokal.

Inovasi lain mendirikan perpustakaan desa, yang bertujuan sebagai sarana edukasi masyarakat juga memberikan opsi lain kepada wisatawan untuk melakukan kegiatan membaca buku sembari berwisata. Inovasi lain adalah mengkatifkan anak kecil dalam kesenian tari. Setiap sore diadakan latihan tari bagi anak-anak, sehingga regenerasi dapa terus berjalan dan jika ada pagelaran kesenian mereka yang akan melakukan pertunjukkan. 


\section{Program Promosi dan Kerjasama}

Promosi merupakan salah satu aspek yang harus dimiliki oleh desa wisata. Hal ini bertujuan untuk memperkenalkan desa wisata beserta seluruh daya tarik dan potensinya kepada wisatawan. Desa Wisata Blue Lagoon telah memiliki agenda resmi promosi yang lebih banyak menggunakan internet dengan blogspot sebagai alat promosinya. Blogspot dari Desa Wisata Blue Lagoon dengan alamat http://bluelagoonyk.blogspot.co.id/ setelah ditelusuri ternyata jarang diupdate. Media promosi dari sosial media yang lain pun juga belum ada. Alat promosi lainnya yang terbukti efektif adalah melalui mouth to mouth. Dari pengalaman yang ada, banyak pengunjung blue lagoon yang datang berkunjung setelah mendengarkan cerita atau mendapat rekomendasi dari teman atau saudara yang telah berkunjung ke blue lagoon.

Sejauh ini pengelola Desa Wisata Blue Lagoon menjalin kerjasama dengan Dinas Pariwisata dan Kebudayaan Kabupaten Sleman, DIY. Blue Lagoon dapat berdiri sebagai desa wisata sesuai dengan arahan dari dinas pariwisata dan kabupaten Sleman. Kerjasama ini berbentuk pendampingan dimana dinas mengadakan pelatihan guiding, manajemen dan SDM untuk pengelola desa wisata blue lagoon. Penyediaan tanda penunjuk jalan juga merupakan hasil dari kerjasama dengan pihak Dinas Pariwisata dan Kebudayaan Kabupaten Sleman, DIY. Kerjasama lainnya dengan melibatkan Mahasiswa yang melakukan Kuliah Kerja Nyata (KKN), sumbangsih yang telah dilakukan adalah dengan bagaimana mempackaging atraksi utama Sendang Pulungan sebagai daya tarik wisata.

Berikut merupakan hambatan yang dialami oleh desa wisata Blue Lagoon semenjak diresmikan menjadi desa wisata dari tahun 2015 oleh Dinas Pariwisata dan Kebudayaan Sleman, maka hambatan yang dihadapi pengelola desa wisata adalah sebagai berikut: (a) Potensi wisata lain belum tergarap dengan baik dan masih mengandalkan Sendang utama. Wisatawan yang datang walau sudah diperlihatkan paket lain yang dimiliki tetap menjadikan embung sebagai pilihan utama, (b) Banyak SDM pengrajin, tetapi mereka belum mempunyai desain yang dapat berjual lebih. Sehingga diperlukan adanya pelatihan dan promosi produk yang baik. 


\section{Kesimpulan}

Berdasarkan hasil penelitian ini, diketahui bahwa pengembangan desa wisata Blue Lagoon telah swadaya dilakukan oleh pengelola desa wisata dengan sumber dana yang berasal dari uang retribusi pemandian tirtha budi. Pengelola telah mampu membuat paket wisata, melakukan promosi, namun hasilnya belum maksimal Kekurangan SDM menjadi kendala dalam pengembangan Desa Wisata Blue Lagoon.

Pemberdayaan masyarakat yang muncul dari kegiatan pariwisata adalah pelibatan masyarakat dalam kegiatan pariwisata. Pengelola desa wisata dilakukan oleh masyarakat sendiri karena mereka yang paling mengetahui kebutuhan dan potensi pengembangan wisata. Dari sisi ekonomi masyarakat juga mendapat manfaat dari keberadaan Blue Lagoon Tirtha antara lain memperluas kesempatan berusaha, meningkatkan pendapatan masyarakat dan mengurangi pengangguran.

\section{Daftar Pustaka}

Ahda, Mustofa. 2017. Pengembangan Desa Wisata Banguncipto. Jurnal Pemberdayaan, Vol.1, No. 1. Hal. 89-94.

Asyfa, W.A. 2014. Partisipasi Masyarakat dalam Pengembangan Pariwisata Di Desa Wisata Alamendah Kabupaten Bandung. SKRIPSI. Universitas Gadjah Mada : Yogyakarta

Brohman, J. 1996. New Directions for Tourism in The Thirld World. Annals of Tourism Research Vol. 23, No 1, hal 48-70

Demartoto, A. 2009. Pembangunan Pariwisata Berbasis Masyarakat. Sebelas Maret University Press. Surakarta

Febriani, S. 2016. Tingkat Partisipasi Masyarakat Dalam Kegiatan Pariwisata Di Desa Wisata Blue Lagoon Dalem Widodomartani Ngemplak Sleman. S1 thesis, FIS.

Hadiwioyo, S.S. 2012. Perencanaan pariwisata pedesaan berbasis masyarakat (sebuah pendekatan konsep). Yogyakarta : Graha Ilmu Hernowo, M. 2000. Perencanaan dan Pengembangan Desa Wisata, makalah disampaikan dalam diklat bidang pariwisata bagi kepala desa di provinsi DIY tanggal 14-16 Agustus 2000. Hal 2.

Inskeep, Edward. 1991. Tourism Planning an Integrated And Sustainable Development Approach. Van Nostrand Reinhold: New York, hal 166 Kabupaten Sleman. 2016. Laporan Klasifikasi Desa Wisata Kabupaten 
Sleman Tahun 2016. Dinas Pariwisata dan Kebudayaan : Sleman, DIY.

Nugroho, I. 2011. Ekowisata dan Pembangunan Berkelanjutan.

Yogyakarta: Pustaka Pelajar.

Nuryanti, W. 2015. The Power Of Culture In Sustainable Development.

International Conference Culture in the Post-2015 Sustainable

Development Agenda. May, 15, 2015. Hangzhou - RRC.

Rogi, C.H. 2015. Dinamika Pengembangan Desa WIsata Brayut di Kabupaten Sleman. Skripsi. Universitas Gadjah Mada. Yogyakarta

Suansri, P. 2003. Community Based Tourism Handbook. REST Project. Thailand

Suhardjo, A.J. 2008. Geografi Pedesaan Sebuah Antologi. Ideas Media: Yogyakarta.

Sutopo,HB. 2002. Metode Penelitian Kualitatif. Sebelas Maret University Press : Surakarta.

Trisnawati Eka Aditya, Wahyono, Hari. Wardoyo, Cipto 2018. Pengembangan Desa Wisata dan Pemberdayaan Masyarakat Berbasis Potensi Lokal. Jurnal Pendidikan: Vol. 3 No. 1. Hal: 29-33. Wahyun, Dinar. 2018. Strategi Pemberdayaan Masyarakat Dalam Pengembangan Desa Wisata Nglanggeran, Kabupaten Gunung Kidul. Jurnal Aspirasi. Vol. 9, No. 1. 